\title{
Menopause in women with chronic immunosuppressive treatment - how to help those patients
}

\author{
Anna Cyganek, Bronisława Pietrzak, Mirosław Wielgoś, Barbara Grzechocińska \\ $1^{\text {st }}$ Chair and Department of Obstetrics and Gynaecology, Medical University of Warsaw, Warsaw, Poland
}

\begin{abstract}
Women after organ transplantation with chronic immunosuppressive therapy or after bone marrow transplantation without such therapy are a growing group of patients. Although their problems in the peri- and postmenopausal period are the same as in healthy women, due to the primary disease and treatment applied they represent a huge challenge from the point of view of their hormonal treatment of menopause. Transplanted women have no particular contraindications for hormonal therapy use. General contraindications, however, such as arterial hypertension, thrombosis in medical history, diabetes, endometriosis, myomas, or active neoplastic disease, have a higher incidence in this group of patients than in healthy women, which significantly influences the possibility of using hormonal therapy. On the other hand, taking into consideration the predisposition for premature menopause in this group, in combination with chronic immunosuppression, it predisposes these patients for higher cardiovascular disease incidence and bone density loss, so hormonal therapy would be highly advisable. Therapy management in transplanted patients requires special care and close monitoring of the transplanted organ. Saving lives with organ transplantation is one of the greatest achievements of contemporary medicine. For long-term improvement of their quality of life, emphasis should be put on regular diagnostic examinations, early detection of abnormalities, and introduction of effective treatment.
\end{abstract}

Key words: menopause, immunosuppressive therapy.

\section{Introduction}

Women with chronic immunosuppressive treatment grow more numerous every year. They are often women suffering from various immunological diseases, who require differentiated immunotherapy forms. Another group of patients are those whose long-persisting diseases lead to organ failure. Of them, the biggest group are those with renal failure, treated with repetitive dialyses or kidney transplantation. Kidney transplantation, like other organs such as liver, heart, pancreas, or lung, has been regarded for many years as the best type of treatment of their insufficiency, unequivocally improving the patient's quality of life. According to estimated Poltransplant data, women represent about one third of all patients with organ transplantation [1].

Poltransplant statistics estimate that there were 1432 vasculated organs transplantations in 2015 in Poland. Most of them are transplantations of kidney, liver, followed by kidney and pancreas, and heart and lung. About 800 bone marrow transplantations are carried out annually.

Women after vasculated organ or bone marrow transplantation are a specific group of patients, but their problems in the perimenopausal period are similar to those faced by other healthy women. It is not, however, a homogenous group. Differences are related to both primary disease and long-term immunosuppressive treatment. In patients after kidney transplantation, cardiovascular diseases are more common, they also receive multi-drug immunosuppressive therapy, which is not the case in patients after liver transplantation, where therapy usually involves only one drug. Women after bone marrow transplantation usually do not receive chronic immunosuppressive therapy, but due to the destruction of gonads in the course of treatment preparing for transplantation, they enter the premature menopause earlier.

Immunosuppressive treatment is significant for the course of the perimenopausal period, and in the group of patients with bone marrow neoplastic diseases, also chemotherapeutic treatment. Chronic use of medicines decreasing immunodefence is one of the methods of acute rejection episodes of prophylaxis, and in the case of their occurrence, they help to controll it and prevent chronic rejection. Currently used immunosuppressive medicines provide proper transplant function support, but also have an important, negative effect on the defensive capabilities of an organism against infections 
and neoplasms. Doses of medicines must be carefully and individually chosen so that they have a positive influence on transplant function upkeep without toxic side effects or infections. Unfortunately, such doses of immunosuppressive medication is called "therapeutic window", and remains fairly narrow. This is why medication choice should always be individual, closely monitored, and should be a combination treatment, which allows the doses to be reduced. Depending on the used immunosuppressive treatment type, there are several adverse effects, which have a crucial influence on the possibility to use perimenopausal period therapy. When cyclosporine is used, such adverse effects include arterial hypertension or thrombotic microangiopathy, which is a common complication in cyclosporine or tacrolimus treatment [2].

In women after organ transplantation, problems requiring special attention involve premature menopause, osteoporosis, and higher neoplastic diseases incidence. Women after bone marrow transplantation are a separate group. Patients after successful transplantation do not receive chronic immunosuppressive therapy; prior chemotherapy, however, leads to destruction of ovary tissue and thus premature menopause. Apart from menopausal symptoms, they might experience graftversus-host disease (GVHD), which, along with vaginal atrophy, may lead to occlusion of the vagina.

\section{Menopause - hot flashes and vaginal atrophy}

Multi-organ insufficiency, especially in patients with liver or renal failure and bone marrow diseases, as well as chronic immunosuppressive treatment, are significant for the moment of occurrence of menopause in women after transplantation. The mean age of menopause occurrence is currently defined as 46-56 years [3]. Premature menopause, however, is defined as occurring before the $40^{\text {th }}$ year of age.

Therefore, on one hand, we have a woman who experienced menopause earlier and thus has a variety of symptoms, which decrease her quality of life, and on the other hand, we have a patient who suffers from various concomitant diseases resulting from the primary disease, who receives immunosuppressive medicines with their numerous adverse effects. All of the abovementioned aspects lead to accumulation of difficulties in help possibilities, limiting the use of hormonal therapy and quality of life improvement.

About $70-80 \%$ of women present menopause symptoms in the form of heat flashes. They are expressed individually from mild, through moderate, to very severe, and depending on the intensity - having effect on natural vital activity, up to disrupting normal activity, especially professional. Treatment alleviating the abovementioned symptoms depends on several fac- tors: symptoms intensity, medical history of the patient, and her personal preferences towards proposed solutions. Women with mild hot flushes can apply various methods, consisting of lowering the temperature in the room, avoiding spicy food, using light clothes, losing weight, as well as using alternative, complimentary therapies such us soy products, isoflavones, phytoestrogens, products from black cohosh. All mentioned treatment methods can be used in the transplanted group of patients without objections. Unfortunately, their therapeutic efficacy is not high $[4,5]$.

In case of moderate and severe intensity of the symptoms, hormonal therapy is applicable: low-oestrogen agents with progestogen, oestrogenic agents in case of prior hysterectomy, selective oestrogen receptor modulators (SERM) - a group of medications acting through oestrogen receptors, and combined therapy, i.e. oestrogen medications with intrauterine system with levonorgestrel.

When choosing oestrogen preparations, one should pay attention to both the type and dose of the agent, as well as the route of administration. Oestrogens used in hormonal therapy are: oestradiol valerate, $17 \beta$-estradiol, conjugated equine oestrogens, piperazine oestrone sulphate salt, and mestranol. In Poland, the most commonly used agents are estradiol valerate and $17 \beta$-estradiol.

Various oestrogenic preparations administered orally have a similar effect. The oral route of administration, however, is connected with more pronounced effect on liver - oestrogens administered orally are transferred through the digestive system, portal vein, and liver. During gastro-intestinal passage, oestradiol is converted into oestrone. The portal vein system quickly transfers absorbed steroids to the liver, there the majority of administered oestrogen is metabolised and inactivated before it reaches systemic circulation. It is called "the first pass effect", and due to its occurrence, oral oestrogens must be applied in higher doses that parenterally to provide efficient control of this process.

Transdermal oestrogens have the same effect as oral oestrogens; this route, however, results in lower risk of venous thrombosis and myocardium infarcts occurrence, and it also has less pronounced influence on serum lipid concentrations in comparison to oral agents $[6,7]$.

Oestrogen preparations applied in the form of creams or dermal gels are less popular, but due to avoidance of the first-pass effect through the liver, which is a common feature of transdermal and subcutaneous therapy, they are worth recommending.

Oestrogens in the form of creams or intravaginal tablets have long been used in atrophic vaginitis treatment, assuming they exert only a local effect. Very low daily doses of intravaginal oestrogens $(0.1 \mathrm{mg})$ have a significant influence on vaginal cytology, without 
raising oestrogen serum concentration. With such low blood concentration, however, the systemic menopause symptoms are not withdrawn, and currently there are no long-term studies proving that even such low doses do not exert a negative effect on the endometrium, if they are administered continuously for a long time. The level of oestrogen absorption from the vagina depends on its state. If the vascularisation is reduced, also absorption is decreased [8].

As mentioned earlier, a specific group of patients among those who underwent transplantation are women after bone marrow transplantation. Those patients after successful transplantation do not receive chronic immunosuppressive therapy; prior chemotherapy, however, leads to destruction of ovary tissue and thus premature menopause. Apart from menopausal symptoms, they might experience graft-versus-host disease. It is a set of symptoms usually concerning skin, oral cavity, eyes, or respiratory system. There have also been cases reported of urogenital manifestation of this disease. It is estimated that this complication may occur even in $25 \%$ of patients, which along with vaginal atrophy can lead to occlusion of the vagina. This has an important influence on the women's quality of life, not only from the point of view of discomfort coming from inflammation, pruritus, and vaginal discharge, but also, in extreme cases, disability to maintain a normal sex life. Taking into account the possibility of the occurrence of this complication, the main stress should be put on prophylaxis, which includes application of local oestrogen therapy in the form of creams and intravaginal tablets. In addition, systemic hormonal therapy may be considered, depending on the age of the patient and concomitant diseases. If there is no response to oestrogen therapy, many clinicians recommend using a steroid agent or cyclosporine locally. At most, surgical treatment is considered. Unfortunately, there are as yet no standard procedures defined for the treatment of this disease [9-13].

Subcutaneous implants seem to be a relatively easy method, not requiring daily medication. They are not, however, available in Poland, which from a patient's point of view, where due to chronic immunosuppression the reaction to a foreign body might be greater than in other women, makes implants a method that is not recommended.

Taking into consideration all of the abovementioned remarks, the choice of oestrogen, as well as its route of administration, should be dependent on whichever menopausal symptom is the most troublesome for the patient. If the dominant symptoms are hot flushes, natural oestrogen applied systemically should be used, with an indication to transdermal formulas. If the problem considers atrophic vaginal mucosa, low-dose therapy of intravaginal agents should be used.

Endometrial hyperplasia and glandular endometrium carcinoma can occur as soon as after six months of imbalanced oestrogen therapy. Thus, the choice of correct progestogen component in women with intact uterus is extremely important. It should be noted that according to published data, women after kidney transplantation have especially high rates of endometrial hyperplasia [14].

Progestogens used in hormone replacement therapy differ in progesterone receptor affinity, as well as androgenic, glucocorticoid, oestrogen, mineralocorticoid, or anti-estrogenic activity. The pharmacologic characteristic components of these medications define their safety profile. Progestogens available for hormonal therapy are: medroxyprogesterone acetate, megestrol acetate, norethisterone, norgestrel, levonorgestrel, dydrogesterone, drospirenone, and micronised progesterone.

Medroxyprogesterone acetate (1.25-2.5 mg daily) is a hormone actively preventing endometrial hyperplasia; it seems, however, unrelated to higher breast cancer incidence risk and, probably, cardiovascular diseases. Taking into consideration transplanted patients with higher risk of both cardiovascular and neoplastic diseases, a progestogen component in hormonal therapy should not be recommended.

Levonorgestrel is a hormone used mostly as oral or transdermal formulation, as well as intrauterine system. According to the literature, especially the intrauterine system for this medication is safe for transplanted women [15].

Drospirenone has progesterone, anti-androgenic and anti-mineralocorticoid activity. It has a protective effect on endometrium, decreases total cholesterol level, and has a positive influence on lipid profile.

Micronised progesterone is a widely used hormone due to its endometrial hyperplasia protection and little effect on lipid profile. In continuous therapy, it is used in a dose of $100 \mathrm{mg}$ daily. There are no medications available with micronised progesterone in Poland, only synthetic progesterone in sublingual and intrauterine tablets $[3,4,16]$.

Publications regarding epidemiological studies suggest the potential danger of long-term progestogen use as an element of hormone replacement therapy. It is stated that the progestogenic component of hormone replacement therapy is responsible for its safety profile to a much greater extent than oestrogen used in this therapy. The most important adverse effects of progestogens used in hormonal therapy concern the cardiovascular system and the mammary gland. Progestogens can be administered orally, intramuscularly, transdermally, or transmucosally (oral cavity, vagina, uterine cavity). For hormone replacement therapy, they are usually administered orally or transdermally.

It should be stressed that transplanted women have no particular contraindications for hormonal therapy use. General contraindications, however, such as arterial hypertension, thrombosis in medical history, diabe- 
tes, endometriosis, myomas, or active neoplastic disease, have a higher incidence in this group of patients than in healthy women, which significantly influences the possibility of using hormonal therapy. On the other hand, taking into consideration the predisposition for premature menopause in this group, as mentioned earlier, in combination with chronic immunosuppression, it predisposes those patients for higher cardiovascular disease incidence or bone density loss, so hormonal therapy would be highly advisable. Therapy management in transplanted patients requires special care and close monitoring of the transplanted organ in 3-6 monthly intervals, and carrying out cytology and ultrasound examination of the pelvis once a year. Breast examinations should also be more frequent than in the group of healthy women.

\section{Osteoporosis}

Bone mass loss is rapid and especially intense 6 to 12 months after transplantation of a vasculated organ. This is due to the immunosuppressive treatment preventing organ rejection. Gradual dose reduction results in improvement in bone density [17]. Stress should be put on decreasing the doses of glucocorticoids as soon as possible and using minimal possible doses in chronic therapy.

The problem of osteoporosis regards especially (almost twice as often) women with autoimmune hepatitis (AlH) and primary biliary cirrhosis (PBC). Livertransplanted women in the perimenopausal period are especially vulnerable to bone density loss due to immunosuppressive treatment, often comprising high doses of glucocorticoids, used directly after transplantation, and cyclosporine, which also has a big influence on bone mass loss. Due to the fact that it is hard to determine the effect of various factors that may have an influence on osteoporosis, such as age, menopause, liver diseases, or liver transplantation, individual therapeutic management should be applied and hormonal therapy implementation should be considered [18, 19].

In the group of kidney-transplanted patients, one of the factors conditioning accelerated bone density loss is the negative influence of glucocorticoids and cyclosporine, in contrast to rapamycin and mofetil mycophenolate. Elevated parathormone concentrations are also significant because they result in bone demineralisation as well as vitamin $\mathrm{D}_{3}$ deficiency [20].

Although patients after bone marrow transplantation do not receive medication intensifying bone mass loss, due to present irreversible gonadal destruction after some time from the transplantation, deterioration of bone density occurs anyway $[17,21]$.

Despite the fact that prophylaxis and osteoporosis treatment is based on using calcium, vitamin D3, bisphosphonates, and calcitonin, hormonal therapy has its important contribution. Polish Gynaecological Association recommendations state that osteopaenia, as well as osteoporosis are indications for hormonal therapy in combination with osteoprotective and calcium agents.

\section{Neoplastic diseases}

Another very important problem among transplanted women in the perimenopausal period concerns neoplastic diseases. There are four potential causes of neoplastic aetiology: genetic, environmental, immunological, and viral infections. Elements that additionally increase the risk of neoplasm occurrence in transplanted patients are immunosuppressive treatment, exposition to UVA and UVB radiation, chronic inflammation, and viral infections, especially EBV, HBV, HCV, and HPV. The most important is the simultaneous presence of immunosuppressive treatment and chronic viral infections [2].

Development happening in transplantology and immunosuppressive treatment significantly prolongs and improves the quality of life of patients after organ transplantation. However, it is the immunosuppressive treatment applied in order to maintain the function of transplant that is responsible for the higher incidence of neoplasms in this group of patients; it is one of the main causes of death of transplanted patients with properly functioning transplant. Neoplasms can occur in multiple organs, but mostly they are located in skin, lungs, digestive tract, and the urinary and lymphatic system. In the discussed group of transplanted women in the perimenopausal period, who are under the surveillance of a gynaecologist, it is important to focus of prophylaxis and diagnostics of genital-deriving neoplasms. So far, no specific rules of neoplasm prophylaxis management have been described for transplanted patients. Basically, the neoplasm screening programme is no different from the one recommended for the general population. Taking into account higher neoplasm risk, however, stress should be put on regular and more frequent (once a year) performance of specific prophylactic examinations for each genital neoplasm [22].

HPV infection is a recognised risk factor of cervical carcinoma and, less frequently, vulvar carcinoma. In transplanted women, the most commonly diagnosed oncogenic virus types are 16 and 18, where neoplasm development risk in this group is 14-16 times higher than in the general population. Taking into consideration those evident facts, special emphasis should be put on performing prophylactic examinations in women after transplantation. Basic examination consists of cytological swabs from the cervix and the newest method - liquid cytology. It is also worth performing tests for HPV DNA. They can be performed as a separate test or as a possibility of performing an additional moleculargenetic test from the same sample in case of carrying out liquid cytology. In the general population, cytology 
is recommended, in case of a correct result, every three years. Due to the abovementioned data, transplanted patients should be examined once a year [23].

Ovarian cancer is an insidious cancer, and its diagnosis is usually made at the advanced development stages. For that reason, there have not been ideal prophylactic schemes prepared yet, it seems that in transplanted women such management should be considered as in patients with diagnosed genetic factor (carriers of BRCA1 and BRCA2 mutations). They are: systematic ultrasound examinations and neoplastic markers in combination with gynaecological examinations once a year [24-26].

Breast cancer is also statistically more frequent in transplanted women. From the prophylaxis point of view, self control and breast examination by the women monthly is very important. However, the only objective examination is regularly performed mammography.

Saving lives with organ transplantation is one of the greatest achievements of contemporary medicine. For long-term improvement of their quality of life, emphasis should be put on regular diagnostic examinations, and early detection of abnormalities and introduction of effective treatment.

\section{Disclosure}

Authors report no conflict of interest.

\section{References}

1. Pietrzak B. Charakterystyka wybranych czynników klinicznych i mikrobiologicznych dolnego odcinka dróg płciowych u kobiet po przeszczepieniu nerki. Oficyna Wydawnicza Warszawskiego Uniwersytetu Medycznego, Warszawa 2009; 184.

2. Durlik M. Czynniki ryzyka choroby nowotworowej u biorców nerki. Rola immunosupresji. II Kurs transplantologii klinicznej. PWN, Warszawa 2008; 29-39.

3. Martin KA, Barbieri RL. Treatment of menopausal symptoms with hormone therapy Literature review current through: Nov 2015. This topic last updated: Jul 07, 2015. Available at: http://www.uptodate.com/ contents/treatment-of-menopausal-symptoms-with-hormone-therapy.

4. Martin KA, Barbieri RL. Preparations for menopausal hormone therapy. Literature review current through: Nov 2015. This topic last updated: Jan 06, 2015. Available at: http://www.uptodate.com/contents/menopausal-hormone-therapy-benefits-and-risks.

5. Baccaro LF, Boin Ide F, Costa-Paiva L, Pinto-Neto AM. Quality of life and menopausal symptoms in women with liver transplants. Rev Bras Ginecol Obstet 2013; 35: 103-110.

6. Pietrzak B, Cyganek A, Jabiry-Zieniewicz Z, et al. Safety and efficacy of hormonal therapy in menopausal kidney-allograft recipients. Transplant Proc 2006; 38: 184-187.

7. Pietrzak B, Wielgos M, Kaminski P, Bobrowska K. Two routes of hormonal replacement therapy in symptomatic menopausal women after kidney transplantation. Neuro Endocrinol Lett 2006; 27: 387-391.

8. Wielgoś M, Mazanowska N, Pietrzak B. Zanikowe zapalenie pochwy: objawy, diagnostyka i leczenie. Prz Menopauzalny 2013; 17: 434-437.

9. Park J, Kim TH, Lee HH, et al. Gynecologic complication of chronic graftversus-host disease: vaginal obstruction. Obstet Gynecol Sci 2013; 56: 277-280.

10. Costantini S, Di Capua E, Bosi S, et al.The management of severe vaginal from genital chronic graft-versus-host disease: diagnosis, surgical technique and follow-up. Minerva Ginecol 2006; 58: 11-16.
11. Bachmann G, Santen RJ. Treatment of vaginal atrophy. Literature review current through: Nov 2015. This topic last updated: Apr 04, 2014. Available at: http://www.uptodate.com/contents/treatment-of-vaginalatrophy.

12. Rechberger T, Kulik-Rechberger B, Winkler I, Perżyło K. Gynaecological aspectsof allogenic stem cell transplantation-incidence, risk factors and preventive strategies-description of two clinical cases and literature review. Gin Pol 2013; 84: 807-810.

13. Falk SJ. Overview of sexual dysfunction in female cancer survivors Literature review current through: Nov 2015. This topic last updated: Dec 16, 2015. Available at: http://www.uptodate.com/contents/overviewof-sexual-dysfunction-in-female-cancer-survivors.

14. Bobrowska K, Kamiński P, Cyganek A, et al. High rate of endometrial hyperplasia in renal transplanted women. Transplant Proc 2006; 38: 177-179.

15. Ramhendar T, Byrne P. Use of the levonorgestrel-releasing intrauterine system in renal transplant recipients: a retrospective case review. Contraception 2012; 86: 288-289.

16. Paszkowski T, Woźniakowska E, Wrona W, et al. The use of micronized progesterone in menopausal hormonal therapy in the light of the most recent study results. Prz Menopauzalny 2011; 4: 267-270.

17. Shane E, Rosen HN. Osteoporosis after solid organ or stem cell transplantation.Literature review current through: Dec 2015. Available at: http://www.uptodate.com/contents/osteoporosis-after-solid-organ-orstem-cell-transplantation.

18. Baccaro LF, Boin Ide F, Costa-Paiva L, et al. Is liver transplantation associated with decreased bone mass in climacteric women? Rev Bras Ginecol Obstet 2012; 34: 335-342.

19. Burra P, De Martin E, Gitto S, Villa E. Influence of age and gender before and after liver transplantation. Liver Transpl 2013; 19: 122-134.

20. Perrin P, Caillard S, Javier RM, et al. Persistent hyperparathyroidism is a major risk factor for fractures in the five years after kidney transplantation. Am J Transplant 2013; 13: 2653-2663.

21. Kananen K, Volin L, Laitinen K, et al. Prevention of bone loss after allogeneic stem cell transplantation by calcium, vitamin $D$, and sex hormone replacement with or without pamidronate. J Clin Endocrinol Metab 2005; 90: 3877-3885.

22. Gaglio PJ, Cotler SJ. Liver transplantation in adults: Long-term management of transplant recipients. Literature review current through: Nov 2015. This topic last updated: Jul 28, 2015. Available at: http://www. uptodate.com/contents/liver-transplantation-in-adults-long-term-management-of-transplant-recipients.

23. Fiedor P, Gardyszewska A, Wojciula J, Szubińska D, Socha M, Wędrzyńska A. Zakażenie wirusem brodawczaka ludzkiego (HPV) jako czynnik ryzyka rozwoju nowotworu u chorych po przeszczepieniu narządów. Il Kurs transplantologii klinicznej. PWN, Warszawa 2008; 177-203.

24. Brennan DC, Rodeheffer RJ, Ambinder RF. Development of malignancy following solid organ transplantation Literature review current through: Nov 2015. This topic last updated: Jan 05, 2015. Available at: http:// www.uptodate.com/contents/development-of-malignancy-followingsolid-organ-transplantation.

25. Carenco C, Faure S, Herrero A, et al. Incidence of solid organ cancers after liver transplantation: comparison with regional cancer incidence rates and risk factors.Liver Int 2015; 35: 1748-1755.

26. Płużański A, Badurak P, Krzakowski M. Nowotwory po przeszczepieniu narządów. Onkol Prakt Klin 2010; 6: 53-61. 